\title{
Pronatalist Policies and Fertility in Russia: Estimating Tempo and Quantum Effects
}

\author{
Asiya Validova
}

\begin{abstract}
This paper examines the family policy reforms of 2007 in Russia that were aimed explicitly at encouraging second and higher-order births, and analyses their impact on fertility. The existing empirical findings about population policy interventions in transition economies are inconclusive, while the most common argument states that policies based on material incentives are insufficient to significantly raise the real fertility in a population. The study aims to offer a better insight to the following research question: was Russian demographic policy effective in terms of raising the fertility level in the country or did it merely change the timing of births? The objective of the paper is to measure two effects of the pronatalist policy in Russia: tempo effect and quantum effect. Using data from the Human Fertility Database, I employ the decomposition method to separate tempo and quantum effects in the observed total fertility rate, and I estimate their relative weight in observed fertility changes. The analysis of period fertility indicators confirmed the prevalence of a tempo effect in observed total fertility rate change, but also revealed a quantum effect of the policy measures, although this was much smaller. Policy impact varied by birth order. For second parity, the tempo effect played a more critical role, while for third parity the quantum effect was more important. Another decomposition approach employed to measure the contributions of various factors in the increase of the number of births during the post-reform period showed the quantum effect which was driven by second and third order births. The study provides empirical evidence of the impact of policies on fertility behaviour, expands the existing analysis of pronatalist measures taken in Russia, and contributes to our understanding of the role of tempo and quantum effects in the recent fertility change in Russia.
\end{abstract}

Keywords: Fertility Rates · Tempo and Quantum Effects • Pronatalist Policies • Births · Russia 


\section{Introduction}

The new population policies introduced by the Russian government in 2007 aimed to encourage larger families to address the massive fertility decline that has posed a demographic challenge since the 1990s. The effectiveness of pronatalist policies depends on their ability to address the major causes of low fertility and reverse a trend toward a small family size. While in some low fertility countries, childbearing postponement and an increase in childlessness have been among the factors driving the fertility decline, in the case of Russia, the prevalence of the one-child family has been the most influential fertility behaviour feature (Elizarov/ Levin 2015). Russia differs from Western low-fertility countries in several aspects: its demographic transition occurred later, and the country has undergone a rapid institutional transformation caused by the collapse of the Soviet Union.

In the communist era, the authoritarian political system and pronatalist ideology were generally favourable for "early and universal childbearing" (Frejka/Giete/Basten 2016). Due to a traditional early marriage and childbearing model associated with the system of job-protected parental leave, state-provided childcare and housing, the Soviet Union was able to maintain relatively high fertility rates; at the same time, female labor force participation rates were also quite high (Frejka/Giete/Basten 2016).

Looking at the historical context, one can conclude that the main tools of the pronatalist policies in the Soviet system were monetary incentives ever since their introduction in the 1930s (Frejka/Gietel-Basten 2016; Elizarov 2019). Adopted in 1944 , the system of lump-sum benefits and monthly childbearing allowances, the increase in maternity leave for female employees and expansion of the network of childcare facilities, as well as measures for the moral encouragement of having many children (the "Maternity Medal" and the title "Heroine Mother") aimed to increase fertility and at the same time were conducive to maintaining a high female labor force participation rate (Elizarov 2019). Similarly, the pronatalist policy introduced in the 1980s, which was designed to stimulate an increase in fertility, was based on financial incentives. Analyses of the impact of family and pronatalist measures adopted by the Communist party at the beginning of the 1980s revealed that, despite the positive response from the population and increase of the period fertility rates, the quantum of fertility remained unchanged, and there was no increase in completed fertility of the birth cohorts; there was only a timing effect (Frejka/Zakharov 2013).

Economic and political instability played a role in fertility decline during the 1990s. This process also coincided with a change in the childbearing pattern from early to later childbearing. The societal transformation brought about job insecurity, expensive housing, and declining childbearing allowances, but it also meant more freedom, leisure, and consumption opportunities. During this time, the ideal of a twochild family weakened and the age pattern of fertility shifted from early childbearing to later ages. Consequently, the number of one-child families became prevalent in Russia (Frejka 2008; Sobotka 2011). Unmet demand for formal childcare facilities had a negative impact on parents' intentions to have more children. The 1990s 
can be described as the period of transformation of fertility behaviour in Russia in response to negligible government family support as manifested by the significant drop in the family allowance. Analyses of cumulated cohort fertility rates by birth order conducted by Frejka and Zakharov (2013) showed that "the main driver of the fertility declines among the 1960s and 1970s birth cohorts" had been a loss of second order births.

In the light of those demographic trends, the dramatic 2007 reform of family policy in Russia aimed explicitly at encouraging couples to have two or more children. The pronatalist agenda included a broad package of family support measures (see Appendix A1). The first measure included substantial increases in pregnancy, birth, and child allowance, and provided favourable parental leave conditions. Another measure which sought to raise fertility directly - giving "maternal capital" (a "baby bonus") to mothers of second and higher-order births - was the most significant initiative of the pronatalist policy. Other government measures included child-care subsidies and tax benefits. In line with the aim of stimulating higher-order births, subsidies for child-care services (for state child-care institutions) were differentiated by birth order. The provision of tax benefits to families with children was another measure; however, tax deductions for parents were negligible, except for tax credits for parents of children with special needs. Pronatalist policies had an immediate effect on the observed period fertility indicators and brought about an increase in the number of births in Russia after 2007.

The purpose of the present paper is to offer a better insight into the efficacy of a pronatalist policy in a country with a transition economy. Russia, largely because of the sheer scale of the latest reforms, makes an interesting case study for addressing the question of whether government support, motivated by pronatalist arguments, affects fertility. The change in demographic policy in Russia was unprecedented in the previous twenty-five-year period; a new financial scheme allowed mothers of second and subsequent newborns or adopted children to become eligible for substantial support. Was Russian demographic policy effective in terms of raising the fertility level in the country or did it merely change the timing of the births? In demographic research, the tempo effect implies that the change in the timing of births (which alters the period fertility rates but does not affect the real fertility rates of the cohorts since the completed cohort fertility) remains unchanged. The quantum effect occurs only if the level of completed fertility - the number of births per woman throughout her reproductive age - changes (Philipov/Kohler 2001). Defining the investigation of the policy effects on the country's fertility level as the primary purpose of the study, I aim to answer the following research question: was the raise in period fertility primarily influenced by the change in the level of fertility (quantum effect) or by the advancement of childbearing in response to monetary incentives provided to mothers (tempo effect)? The study period covers seven years before the reform and ten years after the policy came into effect (2000-2017).

The paper is organized as follows: the next section provides a brief overview of previous research on the efficacy of pronatalist measures of family policy, followed by the formulation of research hypotheses. Section 3 explains the empirical strategy, 
data, and methods adopted for the analysis followed by the results section. The paper concludes with a summary and a further discussion of the findings.

\section{Literature review}

Theoretical approaches linking policies and demographic behaviour stem from the works of various scholars (e.g., Becker 1960, 1965, 1981; Schultz 1973, 1981; Willis 1973; Cigno 1991) who contributed to resolving the problem of analysing fertility as a form of economic behaviour and, in doing so, formulated the new economic approach to family behaviour. This neoclassical economic theory of fertility is based on the postulate that a decision to have a child is a rational decision made by parents as a result of weighing the costs and benefits of childbearing against their income, career preferences, and own perceptions concerning the quality of care provided to children, etc. (Becker 1981; Cigno 1991). These basic assumptions of the economic theory of fertility provide the interpretative framework of how policies might impact reproductive behaviour. Such measures as public subsidies that reduce the cost of childrearing or government transfer payments that raise income are very likely to increase the demand for children (Gauthier/Hatzius 1997). By directly reducing the cost of having a child for working women, public policy can encourage a woman to have a child she would not have had otherwise, resulting in an increase in fertility. Women may also decide to have a child earlier than planned because of this reduction in cost. In other words, two components of fertility may be affected by the introduction of the policy: the tempo effect (concerns the timing of births) and the quantum effect (relates to the total number of children born, including childlessness).

Despite theoretical explanations of the role of public transfers in stimulating fertility, there is an active debate about how to apply the economic framework to improve our understanding of policy as one of the determinants of fertility. It is hard to quantify the effect of any such policy because prevailing demographic trends in the relevant period can substantially affect the fertility behaviour of the population in the country/region. Such phenomena as being in a transition economy, changes in the status of women (e.g., more extended education and higher employment), changing perceptions of what constitutes a family (e.g., cohabitation, divorce), postponement of marriage and childbearing that had taken place in developed countries all had an adverse effect on fertility in recent decades.

As for empirical research, there is no clear-cut evidence regarding the impact of public policies on overall fertility rates. A body of literature that looked at the effects of explicitly pronatalist policies pointed to the success of such measures and their positive effect on fertility (Hoem 1993; Hoem et al. 2001; Lalieve/Zweimüller 2009). These concluded that larger family benefits are associated with higher levels of fertility. However, an extensive literature review by Gauthier (2007) shows mixed evidence regarding demographic policy effectiveness. It is also debatable whether such policies lead to the removal of barriers to higher fertility; they may 
well influence the timing of fertility, but not the completed family size (Blanchet/ Ekert-Jaffe 1994; Gauthier 2007).

There has been far less analysis of family policy interventions in post-communist countries which underwent enormous societal, economic and political transformation in the late 1980s and 1990s. Most studies based on Central and Eastern European (CEE) countries investigate the change in fertility trends and fertility transition that occurred in the region. Their focus was on investigating variation in fertility over time and determining the driving force behind the fertility decline in this group of countries. The possible causes for the sharp fall in fertility after the end of a centrally planned economy include the following: economic and political turmoil associated with high unemployment and economic uncertainty (Ranjan 1999; Kohler/Kohler 2002; Kreyenfeld et al. 2012), and also demographic causes such as the second demographic transition and postponement transition (Zakharov/Ivanova 1999; Zakharov 1997; Billingsley 2010).

Cross-national and national analyses of population policy interventions in transition economies are quite scarce and inconclusive; the evidence of the policy effectiveness is mixed. Frejka and Gietel-Basten (2016) linked the trends in fertility behaviour - such as postponement of childbearing - to different state intervention approaches in CEE countries by providing the first systematic analysis of the relevant family policies since the 1990s, although they underlined their general ineffectiveness. On the other hand, some case-studies on post-communist countries' interventions which had been introduced to fight the decline in fertility after the fall of the communist system showed a significant and differentiated effect on fertility. For example, an increase in the length of child-raising allowance ("fulltime motherhood") in Hungary had a positive effect on fertility among women with low educational attainment, while a generous tax-relief reform increased higherorder birth risks of educated mothers (Spéder et al. 2017).

Although the meta-analysis of fertility trends in transition economies sheds light on the common patterns of fertility behaviour in this group of countries, CEE countries varied substantially in terms of socio-economic development and country-specific demographic trends, as seen by the variation in fertility rates across the region. The total fertility rates (TFR) and women's mean age at birth after 1990 imply that Russia had a different aggregate fertility pattern compared to other countries in the region (Kohler/Kohler 2002). The causes of fertility decline in Russia include economic, socio-cultural and policy-based factors (Koh/er/Kohler 2002; Gerber 2006). For the Russian population, the transition period appeared to apply substantially more constraints to childrearing (compared to other CEE countries); this argument is supported by the evident decrease in the quantum of fertility (Philipov/Kohler 2001).

Most studies that cover the last wave of reforms in demographic policy in Russia are generally quite sceptical about the effectiveness of the measures introduced in 2007. Many authors point to the short-term increase in fertility rate, but attribute this increase predominantly to coincidence with the 1980 cohort (the period of high fertility and a high proportion of higher-order births) reaching its peak reproductive age (Frejka/Zakharov 2013; Elizarov/Levin 2015; Arhangel'skij et al. 2016). Such 
arguments suggest that demographic measures in contemporary Russia may lead to similar outcomes as those introduced in the 1980s - mainly causing a lowering of the age at childbirth and lessening of birth intervals - but they are very unlikely to have a significant effect on real fertility. For example, Frejka and Zakharov (2013) state that family policy measures in Russia designed to encourage higher-order births have little impact on women's decision to give birth to a second and third child; the authors view the policy based on material incentives as insufficient to raise significantly the real fertility in the population. They base their estimates on the Gender and Generation Survey for Russian Federation (the 2011 round) and argue that the 2011 wave of the survey shows that "intentions to have another child were virtually the same as in the 2004 or 2007 rounds" (Frejka/Zakharov 2013). Other scholars who examined the use of the "maternal capital" programme and the attitudes to this family support measure point to the distrust of the policy by Russian women and families as well as to the many bureaucratic obstacles that discourage its utilization (Borozdina et al. 2016). Most demographers who specialize in Russian population policy note that it is too early to make a conclusion about the outcome of the policy of 2007, since the data on completed cohort fertility is not yet available. But the importance of evaluating the family policy early on is well known. This also has advantages, especially in terms of future policy implications.

The inconclusiveness of the existing results on the efficacy of pronatalist policies is associated with many challenges demographers and public economists face when estimating the long-term effects of public policy on population reproductive behaviour. First, most policies are introduced nationwide at the same time, which makes it difficult to determine a causal effect with no information on the potential outcomes in the absence of the policy. Second, the impact of a policy is especially hard to assess in countries that are undergoing changes in demographic behaviour due to demographic, economic and social factors: advancement of childbearing age, childbirth postponement in response to economic uncertainty or societal transformations, changes in perceptions about family structure, marriage behaviour, gender roles and labor market participation. So, the main obstacle here arises from the fact that the timing of births as a result of the policy may also coincide with the progression of the tempo transition (Goldstein et al. 2009). Finally, it can be complicated to differentiate between short-term and long-term outcomes of family policy. Often a temporary shift in fertility behaviour may occur in response to the policy, however, it will not necessarily lead to real changes in reproductive behaviour and have the desired long-term effect. ${ }^{1}$

The present paper aims to contribute to the body of empirical studies that investigate the impact of policies on fertility behaviour and to expand the existing preliminary analysis of pronatalist measures taken in Russia during the past decade.

Two research hypotheses are formulated as follows:

1 An example of this are the pronatalist policies in the German Democratic Republic during the 1970s and early 1980s (cf. Kreyenfeld 2004). 
Hypothesis 1: The pronatalist policy of 2007 in Russia had two effects: tempo and quantum; the tempo effect was prevalent, but the quantum effect was also evident.

Hypothesis 2: The variations in the fertility indicators over the post-reform period are likely to be the result of women having second and third births.

In formulating the hypotheses I was guided by the fact that such an unprecedented increase in family support by government could have had an impact, and to some extent could have encouraged an increase in the real fertility in the country. Moreover, my analysis of the Gender and Generation Survey 2011, which examined women's decision to have a second and third child, also supported the plausibility of this hypothesis (see Appendix A2).

I claim that the quantum effect could be distinguished by means of adjusted period fertility indicators that better approximate the cohort fertility than the total fertility rate. Separation of these two effects enables us to determine the primary reason for the rise in observed fertility, which in turn helps us to assess the effectiveness of the policies in question. Along with this objective, it seems relevant to differentiate these effects by birth order. Since the most important development in the Russian demographic policy concerns second and higher order births, the predominant focus in the paper is on higher parity births.

\section{Data and Methods}

As stated above, the empirical analysis of how policies influence reproductive behaviour is prone to methodological challenges that complicate the assessment of the specific contribution of the policy change. Since Russian demographic policy reforms were applied nationwide, I cannot compare populations affected by the reforms with populations that were not (control group). Moreover, the reforms took effect at the same time for all Russian regions, and although regional family support was also introduced, the magnitude of federal government spending on creating pronatalist incentives for families was significantly larger. Regional family policies varied substantially across the Russian regions in terms of timing, remuneration and eligibility requirements which, along with many demographic and socioeconomic regional differences, makes it methodologically difficult to evaluate the effects of regional policies. For this reason, only the federal programme is the object of primary interest.

Owing to the universal nature of the demographic policy, all women of reproductive age were affected by these policies. I rely on period fertility rates since I do not have data to compare the completed fertility of affected cohorts with the fertility of cohorts born in 1960 in order to estimate the change in fertility before and after the policy implementation. I base the calculations on period fertility data for the Russian Federation obtained from the Human Fertility Database (HFD) of the Max Planck Institute for Demographic Research (Germany) and the Vienna Institute of Demography (Austria). The analysis covers the period 2000-2017, thus examining a ten-year period after the reform took place. From a cohort perspective, different 
cohorts were affected by the new family policy: older cohorts (1970s, 1980s birth cohorts), who are likely to have already started their family formation process at the time of the reform, and younger cohorts (cohorts born in the 1990s), who had to make all their fertility decisions taking the post-reform financial incentives into account. Some cohorts experienced peak fertility before the reforms took place (birth cohorts of 1970-1982) and could not respond to the policy by making changes in their fertility behaviour; others include younger cohorts - whose fertility peak falls in the period of the new policy (birth cohorts of 1983-1986), thus shaping their reproductive behaviour.

The central question in this study is to determine the most appropriate way to measure fertility level by using period indicators. The sensitivity of conventional fertility indicators such as age-specific fertility rates (ASFR) and TFR to the changes in the timing of births - postponement or advancement - inspired extensive literature devoted to the construction of indicators that adjust those fertility measures for this distortion. Moreover, the distortion of the order-specific fertility rates may be caused by the parity composition of the population (Kohler et al. 2002). Therefore, age and parity-specific childbearing probabilities and intensities can be employed to measure the period fertility more accurately (Sobotka 2003). A summary indicator, analogous to TFR, which controls for age and parity was established as parity-ageTFR (PATFR) (Rallu/Toulemon 1994). Although it removes the parity composition bias which is present in the order-specific TFR, PATFR does not ignore the changes in the timing of childbearing among women (Sobotka 2003). As suggested by Bongaarts and Feeney (BF) (1998), a measure of fertility - tempo-adjusted total fertility rate $\left(T F R^{*}\right)$ - overcomes this limitation and allows the separation of tempo and quantum effects in changes of the total fertility rate. ${ }^{2}$

The main novel aspect of the empirical strategy applied in this paper lies in employing several different approaches to estimate the tempo and quantum effects of the policy. First, I adjust the observed fertility measures for various distortions and present a graphical analysis of various indicators used to measure fertility. Second, I decompose tempo and quantum components and estimate their weight in observed fertility rates, adopting a method proposed by Sobotka (2003). A further decomposition approach is also employed and the contributions of various effects

2 Considerable caution is needed regarding the interpretation of tempo-adjustment of TFR. It should be noted that the BF formula relies on the assumed invariant shape for fertility schedule and no cohort effects. By comparing the completed fertility of cohorts with the weighted average of the adjusted TFRs during the reproductive years of these cohorts, Bongaarts and Feeney found relatively close correspondence between the two fertility indicators, and thus validated the adjustment (Kohler/Philipov 2001). This simplifying BF assumption was criticized by a number of scholars (Kohler/Philipov 2001; Van Imhoff 2001). Kohler and Philipov (2001) addressed the shortcoming by proposing an extension of the adjusted TFR that includes variance effects - TFR adjusted to fertility schedules with changing variance (Koh/er/Philipov 2001). However, the sensitivity analysis of $Y i$ and Land (2001) showed that the BF method is generally robust because the annual changes in the shape of the fertility schedules are usually more or less constant, except for very rare cases of extremely large changes (Yi/Land 2001). Moreover, as pointed by Kohler and Phillipov (2001), in Russia the cohort effects are of a very small magnitude, and do not affect the BF-adjusted TFR. 
(with a focus on tempo and quantum) to the increase of the number of births during the post-reform period are measured.

For the first part of the demographic analysis, I use fertility indicators such as the mean age at birth (MAB), TFR, and the tempo-adjusted total fertility rate $\left(\right.$ TFR $^{*}$ ) suggested by Bongaarts and Feeney (1998) on the Russian Federation data in the Human Fertility Database (HFD) (see 4.1. in the Results section). The MAB is calculated from the age-specific fertility rates across the entire range of the reproductive period, and can be also computed for each birth order. Measuring the mean age at birth gains its importance as childbearing postponement becomes a characteristic of the second demographic transition (Philipov/Kohler 2001). Postponement leads to a rise in the mother's mean age at birth, thus decreasing the observed period ASFR and TFR because women delay childbearing until later in life. This has particular relevance for the Russian Federation where postponement of childbearing started in the mid-1990s (about 30 years after the typical pattern for western European countries). The mother's mean age at birth in Russia has been steadily increasing since the 1990s; the age group with the highest fertility rate changed from 20-24 years in the Soviet Union to 25-29 years in the post-Soviet period. At the same time, pronatalist policies can cause women to advance the time of the birth in response to the monetary stimulus, which would have the opposite effect: a reduction of the mean age at birth and a temporary increase in period TFR. The use of order-specific total fertility rates during the period of the advancement of childbirth will thus overestimate the short-run effect of the rise in fertility rates.

To overcome this limitation, I calculate the tempo- and parity-adjusted fertility rate (TFRp* ${ }^{3}$, constructed by Bongaarts and Sobotka (2012), which is based on order-specific fertility but takes into consideration the changing parity distribution of women of reproductive age. Demographers acknowledge that TFRp* yields considerably more consistent results because it eliminates several distortions in the conventional TFR (Bongaarts/Sobotka 2012). It therefore shows the quantum component of the total fertility rate, controlling for the biases discussed above. ${ }^{4}$ Graphical representation of the adjusted fertility indicators along with the MAB for the period in question provides some very valuable insights regarding fertility patterns, but it does not allow us to differentiate between timing and quantum effects in fertility, which facilitates a better understanding of how a demographic policy influences fertility behaviour.

Consequently, in order to evaluate the policy effects more precisely, the second part of the analysis section breaks the fertility measures down into tempo and

3 TFRp* was calculated using the following formula (Bongaarts/Sobotka 2012):

$T F R p^{*}(t)=\sum T F R p^{*}(t, i)=\sum\left\{1-\exp \left[-\sum \frac{p(a, t, i)}{1-r(t, i)}\right]\right\}$. This indicator is the tempo-adjusted version of TFRp $(t)-$ the total fertility rate derived from rates of the first kind (Bongaarts/Feeney 2006). See Bongaarts and Sobotka (2012) for details about fertility indicators.

4 Owing to a lack of data, Kohler and Ortega adjusted PATFR (adjPATFR) which allows separation of "the influence of timing change ('mean tempo effect'). Parity composition ('parity composition effect') on the total fertility rate" (Koh/er/Ortega 2002) was not included in the analysis, and TFRp* was used instead. 
quantum components and estimates their relative weight in observed fertility changes. For this purpose, I relied on the method described by Sobotka (2003), albeit making all necessary case-specific modifications. The rationale of the above study is to combine different period fertility indicators that serve as the best approximates of the cohort fertility for every birth order and to estimate fertility quantum in periods when the postponement of childbearing took place. Sobotka (2003) used the constructed hybrid indicator (comTFR) which "combines adjusted parity-age TFR (adjPATFR) indicator for birth order 1 and 2 with the TFR for birth order $3+$ ". The method used in my work has several modifications that are motivated primarily by the difference in the fertility trend between Russia and Eastern European countries in these two periods, and, secondly, by the limited availability of data. In the Russian case, the advancement of births has been observed for the period following pronatalist reforms. At the same time, childbearing postponement has also been practised since the mid-1990s, and is particularly pronounced for parity one which is consistent with the demographic transition theory. To understand if an increase in observed TFR was driven by the quantum changes in fertility or by the advancement of the births (tempo effects), I use TFRp* for all births combined and for each birth order instead of employing the comTFR hybrid indicator which combines two different indicators that make interpretation difficult.

The third approach used here to separate different effects of the pronatalist policy in Russia is the method developed and described by Sobotka, Lutz and Philipov (2005). This method separates period changes in the total number of births for the period 2006-2017 into a series of effects: changes in the "mean generation size" of women in their reproductive age, changes in fertility timing in tandem with changes in the parity distribution of women (tempo effect) and changes in the level of fertility (quantum effect). ${ }^{5}$ The decomposition method used here allows us to determine the weight of each factor to the absolute change in the number of live births during the post-reform period.

The essence of this method is as follows: I decompose the change in the total number of births into three main components for the period from 2006 to 2017 ( $t_{0}$ and $t_{1}$ respectively) using three indices $I_{G}, I_{T}$ and $I_{Q}$ (results presented in Table 4 in the Results section). 2006 is chosen as a reference year - the year preceding the start of the new policy. The mean generation size $(G)$ is a concept which was introduced by Calot (1984) as an indicator that accounts for the annual number of potential mothers (Sobotka et al. 2005). It links the recorded number of births $B$ in a particular year with the period total fertility rate in that year. ${ }^{6} I_{T}$ is the index of tempo distortion, and it is estimated for each year considered using the following formula: $I_{T}=T F R \div$ TFRp* (as has been noted, I use TFRp* instead of adjPATFR). Since I do the decomposition of change for a period of time, ideally for a benchmark

5 In the paper authors state that "a framework of such decomposition has, however, been suggested earlier" by Ortega and Kohler (2002) and Kohler and Ortega (2004) (Sobotka et al. 2005).

6 The mean generation size is calculated as follows: $G=B \div$ TFR (Sobotka et al. 2005). 
year $\left(t_{0}\right)$, I would ideally choose a year free from tempo effects, so that $B_{0}$ (number of births) remains unaffected by tempo distortions. In this case, however, it is impossible - there is no year with no postponement/advancement of births. I therefore use an alternative method and standardize $I_{T}$ to capture tempo distortions in comparison with the reference year $\left(I_{T(S T A N D)}=I_{T}\left(t_{1}\right) \div I_{T}\left(t_{0}\right)\right)$ to "estimate the hypothetical number of children born, assuming no tempo effects during the period of observation $\left(B_{T}^{\prime}\right)^{\prime \prime}$ by using the formula (Sobotka et al. 2005). Thus, $B$ may be expressed as $B=G \times T F R p^{*} \times I_{T}$. Applying the methodology used in the paper I referred to, it is possible to distinguish between three components of the change in the total number of births by introducing two more indices that contribute to this change: $I_{G}$, which stands for the relative change in the mean generation size $G$ between the years $t_{0}$ and $t_{1}\left(I_{G}\left(t_{1}\right)=G\left(t_{1}\right) \div G\left(t_{0}\right)\right)$, and $I_{Q}$, which stands for the relative change in fertility quantum between the same years $\left(I_{O}\left(t_{1}\right)=\operatorname{TFRp^{*}}\left(t_{1}\right) \div \operatorname{TFRp^{*}}\left(t_{0}\right)\right)$. Therefore, I can express the observed total number of births $B$ in 2017 as a function of the observed number of births in 2006 and the indices of change for this period; it will show us the relative contributions of timing effect, quantum effect and mean generation size effect in the changes in total number of births over this period (see Table 3 in the Results section). ${ }^{7}$

In addition to the decomposition of total indicators of fertility tempo, quantum and mean generation size, I distinguish the changes in these components by birth order, paying particular attention to birth orders 2 and 3 (presented in Table 4 in the Results section). Lastly, I use the extension to the basic decomposition following the method of Sobotka et al. (2005), and decompose the index of tempo distortion $\left(I_{T}\right)$. This incorporates the mutual effect of tempo effect and shift in parity composition into the index of genuine tempo distortion, $/ \tau$, and the parity composition index, $I_{D}$ $\left(I_{T}=I_{D} \cdot \tau\right)$, using the non-adjusted fertility indicator PATFR based on age-parity fertility tables for the calculations of the indices: $I_{D} i=$ TFR $i$ PATFR $i$ and $I_{Q} i=$ PATFR $i$ / adjPATFRi.

My main focus is on the role of the pronatalist policy in Russia that had different effects related to changes in fertility level and timing; the advancement of births is assumed to be the prevailing effect. Therefore, to separate out the effects of the changing tempo and quantum of period fertility in the total number of births in 20072017, it is important to know how many births were "gained" due to changes in the timing of births as result of the family policy. As far as the data are concerned, such statistics as the number of births by women's age and birth parity, and the fertility indicators, were extracted from the Human Fertility Database (HFD). Similarly, I use

$\left.7 B\left(t_{1}\right)=B\left(t_{0}\right) \cdot I_{G}\left(t_{1}\right) \cdot I_{Q}\left(t_{1}\right) \cdot / I_{\text {STAND, } t 1}\right)=B_{0}\left(t_{0}\right) \cdot I_{G}\left(t_{1}\right) \cdot I_{Q}\left(t_{1}\right) \cdot\left(I_{t}\left(t_{1}\right) / I_{T}\left(t_{0}\right)\right)$, and $\Delta B\left(t_{0}, t_{1}\right)=\Delta B_{G}$ $+\Delta B_{Q}+\Delta B_{T}+\Delta B_{g q t}$. Each indicator $\Delta B$ is computed from the corresponding index of change $I$ and the initial number of births $B_{0}$ in year $t_{0} . \Delta B_{g a t}$ represents all the interactions between them. The direct effect of changes in the magnitude of tempo distortion is $\Delta B_{T}\left(t_{0}, t_{1}\right)=\left(I_{T \text { STAND, }}\right.$ $\left.t_{1)}-1\right) \cdot B_{0}$. For the detailed theoretical elaboration of the method see Sobotka et al. (2005) 
TFRp* to estimate the adjusted fertility rates, which are computed using the formula of Bongaarts and Sobotka (2012). ${ }^{8}$

\section{$4 \quad$ Results}

\subsection{Mean age at birth (MAB) and adjusted fertility measures}

I start the investigation of the interplay between the tempo and quantum effects by analysing a variety of measures graphically. The main overall trends are summarized in the figures below. The mean age at birth (MAB) alongside the observed TFR and the adjusted indicators (TFR* and TFRp*) are shown in Figures 1 and 2.

There are two possible reasons for the increase in the mothers' mean age at birth (MAB) that is shown in Figure 1 (panel a). One scenario resulting in an increase of the mothers' mean age is due to the postponement of births - a trend that has affected Russia since the beginning of the 1990s. Another possible explanation for an upward change in the mothers' mean age could be the introduction of the policy measures that gave women in older age groups incentives to have another child. This phenomenon, however, is generally quite rare because younger women tend to be more responsive toward monetary stimuli in the demographic policy. In the case of Russia, until 2006 one can observe an increase in the mean age of mothers for all births combined due to birth postponement. Starting from 2007, the mean age at first birth still demonstrates the continuing postponement process, while an increase in mean age at second and third births throughout 2007-2017 is different in nature: older women with one or more children respond positively to the fertility stimulus.

The lowering of the mothers' mean age can also be influenced by a range of factors. The MAB decreases as the fertility of younger women increases; it may happen if women of younger ages respond to the public policy more actively than older women, or react positively to favourable economic conditions (economic growth). In this case the advancement takes place; women have children earlier than they initially planned (timing effect). Another plausible explanation of the decrease in the mean age at birth lies in the more active response to the demographic policy by younger age groups (age-specific quantum effect). The graphical analysis of the mothers' mean age at different birth orders illustrates how in 2010 there was a downward movement for birth order 2 and 3 while MAB1 exhibited a gradual increase during the same period (Fig. 1 (panels b, c, d)). As for MAB1, I attribute the slight increase to the continuing birth postponement; women who had not had

8 The paper of Sobotka et al. (2005) that employs this decomposition method bases the calculation of adjusted fertility indicators on a simplified version of the adjustment method proposed by Kohler and Ortega in 2002 and combines them with TFR for birth order 3 and higher. I do not have the detailed data necessary for the computation of the Kohler-Ortega adjustment and therefore replace them with TFRp* for all parities; I consider it to be the best tempo- and parityadjusted measure, and I have all the necessary data for its computation. 
Fig. 1: Mean age at birth for women by parity and combined in Russia (20002018)
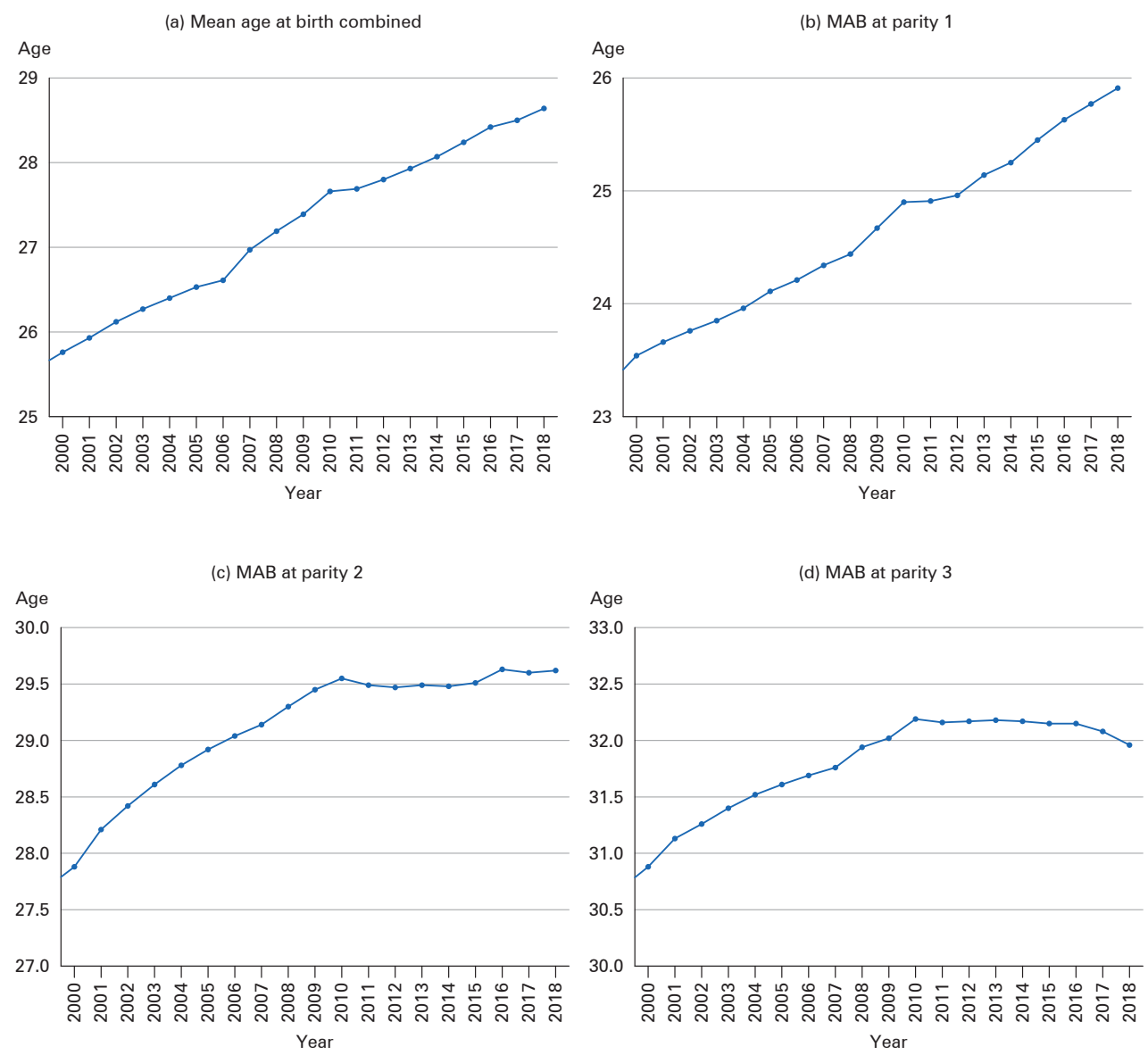

Source: Constructed based on data from HFD

children during the economic turmoil of 2008 due to the higher economic uncertainty postponed their first childbirth, but the figures recuperated after the country started to come out of recession in 2010.

Regarding the changes in mean age changes for higher parities, Figure 1 (panels c, d) shows that MAB2 and MAB3 had been stagnating since 2010; the reason might be the fact that advancement of childbirth for parity two and three contributes to this trend (timing effect). Had that not been the case, one would have seen an increase in MAB2 and MAB3 caused by the overall trend of birth postponement in Russia. However, I assume that the quantum effect is also present here: at the outset of the economic crisis, the youngest subgroup of women with one or more children reacted more actively to the pronatalist policy ("maternal capital" in particular), therefore providing downward pressure on the mothers' mean age at second and 
Fig. 2: Observed and adjusted total fertility rates by parity in Russia (20002017)
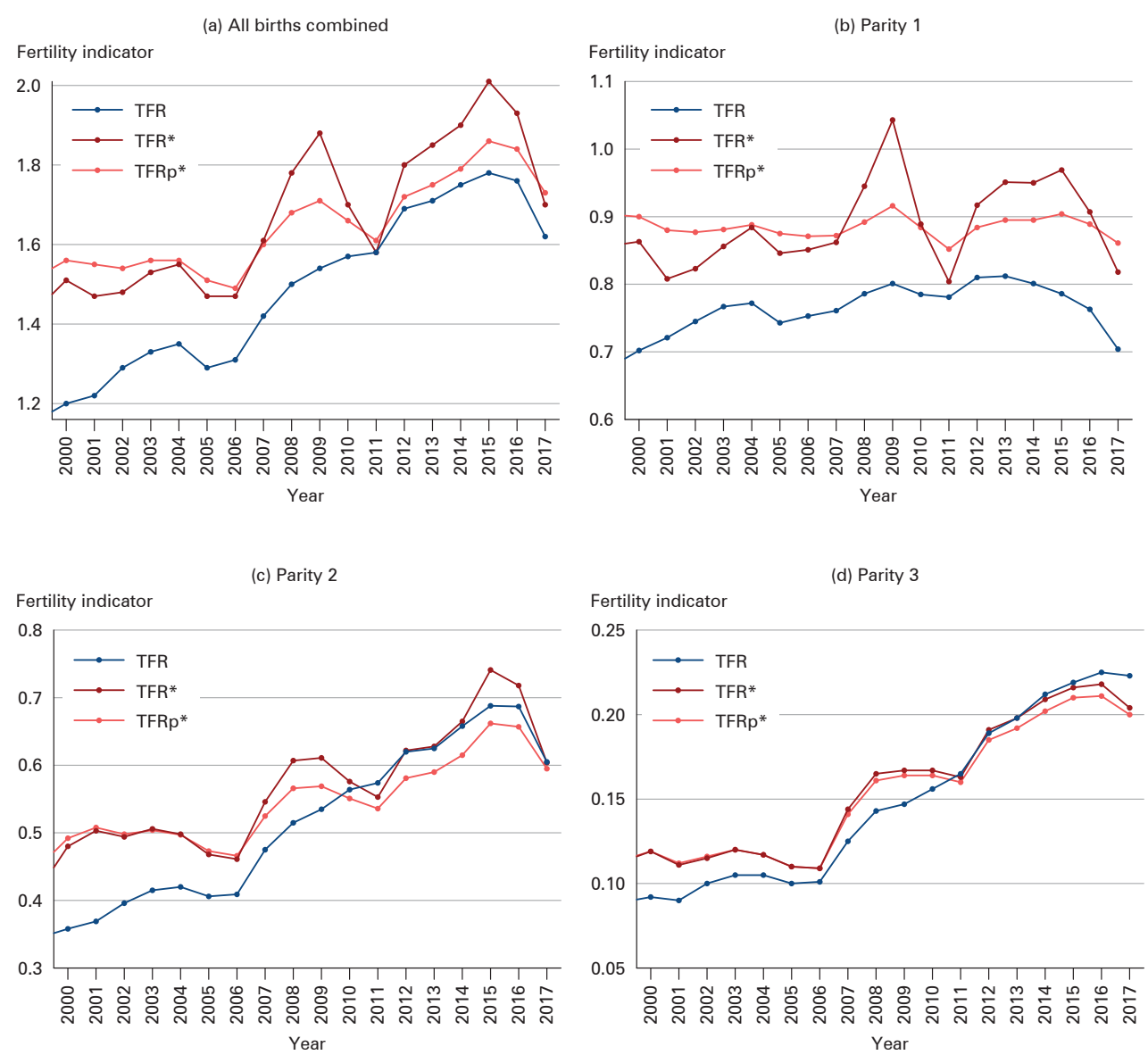

Source: Data combined from HFD and author's calculations based on HFD data

third births. This observation is consistent with my second explanation for the cause of decrease of mean age at birth.

As for fertility rate measures (presented graphically in Fig. 2), my predominant focus is on the analysis of changes of TFRp* for all births combined and TFRp* for parity 1, 2 and 3. Bongaarts and Sobotka (2012) highlighted the usefulness of this indicator for its ability to control for the composition of women by parity and to assess the undistorted quantum of period fertility. Additionally, I will refer to the patterns of change of two other fertility measures - TFR and TFR* - where appropriate.

Following the demographic policy reform, an increase in all fertility measures can be seen for several years: TFR, TFR* and TFRp* dynamics suggest an immediate effect of the policy implementation. TFR* and TFRp* are considerably higher than 
TFR from 2007 to 2009, just as they were for the years before the launch of the new policy (Fig. 2). This trend indicates the existence of birth postponement throughout the period driven by birth postponement for the first parity: the mean age at birth for all births combined has been increasing. TFR grew from 1.3 in 2006 to 1.78 in 2015 and then declined to 1.57 in 2018. At first, TFR* and TFRp* also increased in line with an upward trend established at the end of 2006. Remarkably, the adjusted fertility indicators moved in the opposite direction in 2009-2011; the visual representation of the variables' dynamics shows that both TFR* and TFRp* diverged and fell during this period, and only afterward did a growth trend emerge. My explanation is based on several factors (examined below) that affect changes in MAB and on adjusted fertility indicators for birth orders of different parity.

As stated above, changes in TFR1 have not been influenced by the introduction of the pronatalist policy package. For that reason, and due to the absence of data concerning the motivation to have children by this group of women during the period of analysis, one cannot accurately estimate the extent of tempo and quantum changes in TFR1. Examining the fertility rate for birth order 1, I turn the focus to TFR1 because, due to the increase of MAB1, the TFR1 dynamics appear highly distorted. As we know, the birth postponement trend is more pronounced for the lower birth orders. Figure 2 (panel b) demonstrates the increase in TFR1* throughout 20052009 , presumably caused partially by economic growth in the country and partially by the effects of the demographic policies. Overall, this increase in TFR1* was followed by a sharp drop in the indicator, as Russia had been hit by the worldwide Great Recession of 2008; TFR1* continued to decrease through 2011. A rapid increase of MAB1 in 2008-2010 indicated that women had reacted to the economic crisis by postponing their first birth; however, improvement in the economic conditions applied downward pressure to MAB1 over the post-crisis period (Fig. 1, b). From 2012 onward, the overall tendency towards postponement of the first child continued, and, starting from 2015, there was a considerable decline in all three fertility indicators.

A closer look at the variations of fertility rates for higher-order births in Russia reveals interesting fertility behaviour trends (Fig. 2 (panels c, d)). The increase in all fertility indicators in combination with a growing mean age at birth for second and third parity until 2010 could indicate a small quantum effect during the period (as women of a young age group also contributed to changes in TFR2). Interestingly, the mean age stopped rising in 2010, pointing to a policy-related birth advancement trend (tempo effect). As for fertility rates, in 2010-2011 adjusted indicators for higher parities showed virtually no change and even a slight decrease (crisis effect), but continued their upward trend in 2011-2015 (2011-2016 - for the third parity) which, according to my proposition, points to the presence of a small quantum effect. The rapid decline in fertility from 2015 as shown by the decrease in TFRp* provides evidence that the policy measures are indeed short-lived and not substantial enough to increase real fertility, especially when other macro factors such as sluggish economic growth, a growing proportion living in poverty, plunging real wages, and overall economic stagnation are also discouraging people from having more children. 
To sum up, a fall in the TFR* and TFRp* in 2009-2011 could be explained by different factors: firstly, the TFR* for first parity decreased in 2009-2011 as MAB1 in 2008-2010 increased (due to birth postponement during the crisis); secondly, there was no growth in the TFR* for higher-order births and even decreased slightly. Combined, these factors lowered the TFR* and TFRp*. This observation confirms the hypothesis about the timing effect's prevalence in response to the pronatalist measures: despite the overall trend of childbearing postponement, in the postintervention period, the lowering of the mean age at second birth narrows the interval between first and second births. In other words, women decided to have their second child earlier than they would have in the absence of the policy.

\subsection{Estimation of tempo and quantum effects in TFR}

Using the framework developed by Sobotka (2003) for childbirth postponement, I estimate tempo and quantum elements of fertility change in Russia for the period which followed the introduction of the family policy. In Table 1 I compare orderspecific and overall TFR for 2017 with TFRp* by birth order and for all births combined. In order to represent the quantum effect - the real increase in the fertility level - I first constructed the index of change of quantum, which is computed as a ratio of TFRp* in 2017 to TFRp* in 2007, and I then computed a coefficient $\left(I_{Q}-1\right)$ that is used to establish the quantum part of the difference between the observed TFR in 2017 and 2007. The difference between the change in observed TFR in 2007 and 2017 and the calculated quantum effect estimates the timing effect. To enable comparison of the timing and quantum effects for pre- and post-reform periods I also reproduced these calculations for the period prior to the policy intervention (2000-2006) (Table 2).

The results for the post policy period demonstrate that estimated tempo and quantum components vary by birth order (Table 1). The quantum effect for parity 1 was negligible because the family policy reforms targeted those who already had at least one child. Therefore, the change in TFR1 is mostly due to the timing of births. For higher-order births we see a different picture: the tempo effect for parity 2 is prevalent; however, there is a small quantum effect for the second birth order (13 percent). With increasing parity, the quantum effect becomes the more important factor. For birth order 3, 42 percent of the increase in TFR3 is driven by the change in the real level of fertility. The TFR results for all births combined indicate the prevalence of the tempo effect, suggesting that overall TFR increased to a considerably larger extent due to the advancement of births. There was also a change in the quantum and was estimated at 9 percent for TFR. Results for the time period which preceded the policy, presented in Table 2, indicate virtually no quantum effect in the TFR. Even for the second and third parities, the quantum effect is very small, which is consistent with the observation that it did not boost TFR2 and TFR3 prior to the reforms. 
Tab. 1: Quantum and tempo effects in TFR by birth order in Russia between 2007 and $2017^{*}$

\begin{tabular}{llccr}
\hline & Birth order 1 & Birth order 2 & Birth order 3 & Total \\
\hline 1 TFR 2007 & 0.761 & 0.475 & 0.125 & 1.416 \\
2 TFR 2017 & 0.704 & 0.605 & 0.223 & 1.621 \\
3 Reduction in TFR(2)-(1) & -0.057 & 0.130 & 0.098 & 0.205 \\
4 TFRp* 2007 & 0.871 & 0.525 & 0.141 & 1.590 \\
5 TFRp* 2017 & 0.861 & 0.595 & 0.200 & 1.728 \\
6 IQ (5)/(4) & 1.012 & 1.133 & 1.418 & 1.087 \\
7 IQ-1 & 0.012 & 0.133 & 0.418 & 0.087 \\
8 quantum effect(3)*(7) & -0.001 & 0.017 & 0.041 & 0.018 \\
9 tempo effect(3)-(8) & -0.056 & 0.113 & 0.057 & 0.187 \\
10 quantum effect \% & 1 & 13 & 42 & 9 \\
11 tempo effect \% & 99 & 87 & 58 & 91 \\
\hline
\end{tabular}

* Estimation of tempo and quantum components in TFR change was made largely based on the method suggested in Sobotka (2003: 188-189).

Source: Author's calculations based on HFD data

Tab. 2: Quantum and tempo effects in TFR by birth order in Russia between 2000 and 2006

\begin{tabular}{lrrrr}
\hline & Birth order 1 & Birth order 2 & Birth order 3 & Total \\
\hline 1 TFR 2000 & 0.702 & 0.358 & 0.092 & 1.196 \\
2 TFR 2006 & 0.753 & 0.409 & 0.101 & 1.305 \\
3 Reduction in TFR(2)-(1) & 0.051 & 0.051 & 0.009 & 0.109 \\
4 TFRp* 2000 & 0.900 & 0.492 & 0.119 & 1.560 \\
5 TFRp* 2006 & 0.871 & 0.466 & 0.109 & 1.492 \\
6 IQ (5)/(4) & 0.968 & 0.947 & 0.916 & 0.956 \\
7 1-IQ & 0.032 & 0.053 & 0.084 & 0.044 \\
8 quantum effect(3)*(7) & 0.002 & 0.003 & 0.001 & 0.005 \\
9 tempo effect(3)-(8) & 0.049 & 0.048 & 0.008 & 0.104 \\
10 quantum effect \% & 3 & 5 & 8 & 4 \\
11 tempo effect \% & 97 & 95 & 92 & 96 \\
\hline
\end{tabular}

Source: Author's calculations based on HFD data

\subsection{Decomposition of tempo and quantum effects in the total number of births}

The results of decomposing the quantum, tempo and mean generation size effects in the total number of births are presented in Table 3. One can see positive effects of fertility quantum and fertility advancement in the change of the number of births; but 
Tab. 3: Decomposition of changes in the total number of births and relative contribution of the main factors from the beginning of the pronatalist policies in Russia (2007-2017)

\begin{tabular}{lr}
\hline Reference year $t_{0}$ & 2006 \\
Analyzed period $t_{1}$ & $2007-2017$ \\
Births in the reference year $t_{0}$ & $1,479,637$ \\
Hypothetical births in $t_{0}$ (without tempo effects) & $1,692,949$ \\
Mean annual births in $t_{1}$ & $1,774,870$ \\
Mean annual gained births in $t_{1}$ & 81,921 \\
Of which due to & \\
Tempo effects & 1,147 \\
Quantum changes & 12,944 \\
Mean generation size $G$ & $-3,441$ \\
Interaction & 1,106 \\
$\%$ & \\
Tempo effects & $1.40 \%$ \\
Quantum effects & $15.80 \%$ \\
Mean generation size $G$ & $-20.32 \%$ \\
Interaction & $1.35 \%$ \\
\hline
\end{tabular}

Source: Author's calculations based on HFD data

they were partially offset by a decrease in mean generation size over the observed period. That happened because the large birth cohort of women born in the 1980s started to leave the fertility peak reached in the early 2000s. Table 3 contains an evaluation of births "gained" due to the advancement of childbirths during the whole period since the launch of the new family policy. To assess the relative long-term contribution of each considered factor, I estimated mean annual births "gained" due to those factors by relating them to the hypothetical number of births in 2006 had the family policy not taken place and advancement of childbearing not occurred. Results summarized in this table show the overall effects of three components of change on the "additional" number of births.

Overall, two features stand out regarding the major effects. First, the tempo effect increases the number of births only by 1.4 percent in comparison with 2006. Second, the change in fertility quantum over the analysed period had an even stronger impact on the increase in the number of births (15.8 percent). Mean generation size was the important factor and was negative for this period, which means that it went in the opposite direction and contributed to the decline in fertility rates. Overall, these results support the conclusion that the examined pronatalist policy could lead to both tempo and quantum effects; change in quantum and tempo distortions had a positive influence on the absolute number of births after the reform had taken effect.

Table 4 illustrates how the contribution of the major factors that influence the changes in the number of births varies for each parity. As for mean generation size 
Tab. 4: Decomposition of change in the number of births in Russia by parity (2017 compared with 2006) and decomposition of the index of tempo distortion IT in Russia in 2017*

\begin{tabular}{|c|c|c|c|c|}
\hline & Parity 1 & Parity 2 & Parity 3 & Total \\
\hline Births $\left(B\left(t_{0}\right)\right)$ in 2006 & 880,026 & 448,659 & 150,950 & $1,479,635$ \\
\hline Births $\left(B\left(t_{1}\right)\right)$ in 2017 & 656,607 & 654,548 & 250,969 & $1,664,615$ \\
\hline$B\left(t_{1}\right) / B\left(t_{0}\right)$ & 0.746 & 1.459 & 1.663 & 1.125 \\
\hline $\operatorname{TFRi}\left(t_{0}\right) 2006$ & 0.753 & 0.409 & 0.101 & 1.305 \\
\hline $\operatorname{TFRi}\left(t_{1}\right) 2017$ & 0.704 & 0.605 & 0.223 & 1.532 \\
\hline TFRp* 2006 & 0.872 & 0.466 & 0.109 & 1.490 \\
\hline TFRp* 2017 & 0.861 & 0.595 & 0.200 & 1.728 \\
\hline$G\left(t_{0}\right) 2006$ & $1,168,693.227$ & $1,096,965.770$ & $1,494,554.455$ & $1,133,819.923$ \\
\hline$G\left(t_{1}\right) 2017$ & $932,680.398$ & $1,081,897.521$ & $1,125,421.525$ & $1,086,563.316$ \\
\hline$I_{G}\left(t_{1}\right)$ & 0.798 & 0.986 & 0.753 & 0.958 \\
\hline$I_{Q}\left(t_{1}\right)$ & 0.987 & 1.277 & 1.835 & 1.158 \\
\hline$I_{T}\left(t_{0}\right) 2006$ & 0.864 & 0.878 & 0.927 & 0.875 \\
\hline $\mathrm{I}_{\top}\left(t_{1}\right) 2017$ & 0.818 & 1.017 & 1.115 & 0.887 \\
\hline$I_{\text {T STAND }}\left(t_{1}\right) 2017$ & 0.947 & 1.159 & 1.203 & 1.014 \\
\hline \multicolumn{5}{|c|}{$I_{T}$ decomposition in $2017:$} \\
\hline PATFRi 2017 & 0.819 & 0.532 & 0.190 & 1.636 \\
\hline$I_{T}\left(t_{1}\right) 2017$ & 0.818 & 1.017 & 1.115 & 0.887 \\
\hline$I_{D}\left(t_{1}\right)$ & 0.860 & 1.137 & 1.174 & 0.936 \\
\hline$/ \tau\left(t_{1}\right)$ & 0.951 & 0.894 & 0.950 & 0.947 \\
\hline
\end{tabular}

* Calculations of the decomposition indices in the following tables have been made employing the methodology of Sobotka et al. (2005) used for Hungary, Poland and Spain in the cited paper.

Source: Author's calculations based on HFD data

factor, it differs by birth order but makes a negative contribution for all three parities. This observation is supported by the fact that a large cohort of women are ageing and leaving their fertility peak. Generally, the effect of $\mathrm{I}_{\mathrm{G}}$ for all births combined remains relatively stable at 0.95 .

The influence of the quantum component is characterized by marked differences by birth order: the positive effect of the fertility quantum index $\left(I_{Q}\right)$ is the largest for parity 3 and becomes smaller for parity 2, whereas for parity 1 it is just under 1 (0.99). Subsequently, the fertility quantum increased strongly for birth order 3 and moderately for birth order 2 , thus indicating the difference in the interpretation of changes in the total number of births caused by including order-specific indices in the analysis. The positive total effect of the fertility quantum supports the assumption of the existence of the quantum effect. The standardized index of tempo distortion is at its maximum for parity 3 (1.2); while its influence on parity 2 is smaller, and for parity 1 turns negative. The index of tempo distortion $I_{T}$ captures the collective 
influence of tempo effects and the shifts in parity composition (Sobotka et al. 2005). Here the tempo index is decomposed into two components: index of genuine tempo distortion $(/ \tau)$ and index of parity composition $\left(I_{D}\right)$. All the indices discussed here are presented in Table 4. For parity 2 and 3, parity composition had a positive effect, while genuine tempo distortion was less than 1 . The results for all birth combined, which capture the negative effects of both indices for parity one, show that tempo distortion was explained to an equal extent by the genuine tempo effect (0.95) and by the parity composition (0.94).

To sum up, the application of such decomposition for different parities uncovered marked differences in the weights of the tempo and quantum components.

\section{Conclusions and Discussion}

This paper explores the effectiveness of population policy. Its main focus is on a set of pronatalist reforms introduced in Russia in 2007, the intention of which was to encourage mothers to have more births and raise further children. The bulk of empirical evidence with regard to policy effectiveness in different countries to date provides no plausible link between an increase in long-term fertility and government policies. In the case of Russia, the new round of pronatalist benefits had a positive effect on observed period fertility indicators, demonstrated by the increased number of births and the steady upward trend in the period total fertility rate in Russia following the implementation of the policy. However, a mere rise in observed fertility rates does not mean that the family policy efforts actually affect completed fertility; therefore, an analysis of the timing of births is of particular importance. Given that reforms were based on creating monetary incentives for families, I investigated the following research question: was the raise in period fertility primarily influenced by the change in the level of fertility (quantum effect) or by the advancement of births in response to monetary incentives provided to mothers (tempo effect)? This study, therefore, aimed to contribute to our understanding of the role of tempo and quantum effects in the recent fertility change in Russia, which has not yet been sufficiently explored in the existing literature.

The main novel aspect of the present evaluation of the family policy is the application of a multi-method approach, which makes it possible to investigate the nature of change in several fertility indicators and enables the results obtained to be compared in methodologically different ways.

In the first part of the study, I provided a descriptive analysis of such indicators as mothers' mean age at birth, TFR, and alternative fertility indicators (TFR* and TFRp*) that eliminated common distortions. Adjusting for timing and parity revealed differences in the patterns of change of the indicators for different parities. Higher order fertility thereby increased due to possible effects of the policy, while first parity rates and mean age at birth of the first child did not change and only varied due to the economic crisis and the continued trend of birth postponement. As for the tempo-quantum interplay, changes in adjusted fertility rates and the lowering of the mean age at birth for parity 2 and higher generally supported the "advancement 
of births" hypothesis, but stabilization of MAB2 and MAB3 from 2011 combined with an increase in adjusted fertility rates for those parities suggested the possibility of a quantum effect.

Further, I presented two ways to estimate the contribution of tempo and quantum effects in the increase seen in the period fertility indicators that followed the pronatalist policy launch in Russia. Although the contribution of tempo effects has been extensively studied in the context of birth postponement and the reduction of fertility rates in Europe (Kohler et al. 2002; Lutz et al. 2003; Sobotka 2004), decomposition of the tempo and quantum effects in the context of policy-induced advancement has not yet been thoroughly examined. Furthermore, the influence of these effects on total births in Russia has not been investigated either so far. The two methods employed in the analysis largely followed the approach of Sobotka (2003), whereas those of Sobotka, Lutz and Philipov (2005) were applied in the case of birth advancement in Russia. The first approach separated tempo and quantum effects in observed total fertility rate over the analysed period, thus allowing an assessment of the role of the advancement of births provoked by policy incentives in the period fertility rise. As for total fertility rate for all births combined, the results support the widely-held view that the tempo effects are the primary driving force behind the ensuing increase in period fertility. But the results also identified a quantum effect (9 percent) supportive of the first hypothesis of the current study. Differentiation by birth order reveals a different picture: while second-time mothers changed the timing of birth (tempo effect prevalent), the fertility rates for third births changed due to both tempo and quantum effects. The quantum effect for the first parity was negligible, which supports the second hypothesis regarding the main role of second and third births in the period fertility increase.

The second approach taken in this paper also provided evidence of how the interpretations of change in fertility are modified once order-specific components are taken into consideration. In that part of the analysis, I measured different effects of policy on the total number of births by separating the overall change in births into three components: changes in the "mean generation size" of women in their reproductive age, changes in the level of fertility (quantum effect), and changes in fertility timing combined with changes in the parity distribution of women (tempo effect) (a method proposed by Sobotka, Lutz and Philipov (2005)). As for the relative contribution of the fertility quantum component, this increased the number of third births, while for birth order two its weight was shown to be less pronounced. Overall, the estimated size of the effects on the change in the total number of live births consistently supported the presence of both tempo (1.4 percent) and quantum effects ( 15.8 percent); and the fertility quantum impact was stronger than the impact of the tempo effects. The mean generation size had a negative effect, indicating a decrease in the number of women of primary reproductive ages. This finding supports the proposition discussed in the literature about the temporary fertility increase which coincided with the 1980 cohort (the period of high fertility in response to pronatalist measures introduced in the 1980s) reaching its peak reproductive age (Frejka/Zakharov 2013; Arhangel'skij et al. 2016) 
In summary, the main conclusions with regard to fertility dynamics since Russia introduced its new policy in 2007 are as follows: along with the rise of period measures of fertility such as total fertility rate, indicators adjusted for timing and parity nevertheless demonstrate an increase in the level of fertility. Two methods utilized in the study used very different decomposition approaches for timing and quantum effects, and, therefore produced different results. However, both supported the existence of the quantum effect, which was the general research question of the paper. Some expected results emerged regarding the influence of the pronatalist policy on the timing of births; family policy based on birth-related monetary incentives did change fertility behaviour in terms of an advancement of births, especially during the first years of the new policy regime. The order-specific decomposition of tempo and quantum effects revealed a clear difference in the relative contribution of these effects to second and third births.

However, the rapid decline in fertility rates observed from 2015 suggests that the analysed demographic policy cannot be classified as successful in the long run. This supports the widely held view that explicit pronatalist policies generally influence the timing of fertility and not the completed family size (Gauthier 2007). The presence of a quantum effect, as found in this study, indicates that the goal of increasing the level of fertility has been achieved to some extent, but it may still be quite shortlived. The present empirical analysis leads to the conclusion that although the policy significantly raised benefits from a previously relatively low level, it did not have a clearly positive effect on long-term fertility. The most plausible explanation of the phenomenon is the fact that, in Russia, the principal tools for reaching a demographic goal remain financial. International evidence and the results of this study show that the most effective family policy model is one which not only offers financial benefits to families, but where there is also comprehensive support through social changes towards gender equity and family-friendly policies that help women combine work and childrearing, as well as accessible institutional childcare.

A final word of caution concerns the limited analysis of fertility from the period perspective. As has been noted, I did not have enough data to look at completed fertility for all relevant cohorts. Although attempts have been made to eliminate biases in TFR by adjusting it for tempo distortions, there is room to improve the results, for example by incorporating Kohler-Ortega adjustment. More detailed investigation of how family policies are linked to cohort fertility is therefore left for future exploration.

\section{Acknowledgements}

l express the deepest appreciation to Joachim Singelmann, Ph.D. Professor Emeritus at the University of Texas at San Antonio for his valuable comments and guidance in the process of working on this article. 


\section{References}

Arhangel'skij, Vladimir; Ivanova, Alla; Rybakovskij, Leonid 2016: Rezul'tativnost' demograficheskoj politiki Rossii. Moscow: Jekon-Inform.

Becker, Gary 1960: An economic analysis of fertility. In: Coale, Ansley (Ed.): Demographic and Economic Change in Developed Countries. Princeton, NJ: Princeton University Press: 209-231.

Becker, Gary 1965: A theory of the allocation of time. In: The Economic Journal 75,299: 493-517. https://doi.org/10.2307/2228949

Becker, Gary 1981: A treatise on the family. Cambridge: Harvard University Press.

Billingsley, Sunnee 2010: The post-communist fertility puzzle. In: Population Research and Policy Review 29,2: 193-231. https://doi.org/10.1007/s11113-009-9136-7

Blanchet, Didier; Ekert-Jaffe, Olivia 1994: The demographic impact of fertility benefits: evidence from a micro-model and from macro-data. In: Ermisch, John; Ogawa, Naohiro (Eds.): The family, the market and the State in aging societies. Oxford: Clarendon Press: 79-104.

Bongaarts, John; Feeney, Griffith 1998: On the quantum and tempo of fertility. In: Population and Development Review 24,2: 271-291. https://doi.org/10.2307/2807974

Bongaarts, John; Feeney, Griffith 2006: The quantum and tempo of life-cycle events. In: Vienna Yearbook of Population Research 4: 115-151. https://doi.org/10.1553/populationyearbook2006s115

Bongaarts, John; Sobotka Tomáš 2012: A demographic explanation for the recent rise in European fertility. In: Population and Development Review 38,1: 83-120. https://doi.org/10.1111/j.1728-4457.2012.00473.x

Borozdina, Ekaterina et al. 2016: Using maternity capital: Citizen distrust of Russian family policy. In: European Journal of Women's Studies 23,1: 60-75. https://doi.org/10.1177/1350506814543838

Calot, Gerard 1984: Une notion intéressante: L'effectif moyen des generations soumises au risque. I. Présentation méthodologique. In: Population 39,6: 947-976. https://doi.org/10.2307/1533042

Cigno, Alessandro 1991: Economics of the family. Oxford: Clarendon Press.

Elizarov, Valeriy; Levin, Victoria 2015: Family policies in Russia: could efforts to raise fertility rates slow population aging? Russian Federation aging project [electronic resource]. World Bank, Washington, D.C. [https://openknowledge.worldbank.org/ handle/10986/22614 License: CC BY 3.0 IGO, 29.11.2020].

Elizarov, Valeriy 2019: The 75th anniversary of Russia's pro-natalist policy and other memorable dates. Demographic calendar 2019. In: Population and Economics 3,4: 101-120. https://doi.org/10.3897/popecon.3.e49761

Frejka, Tomas 2008: Parity distribution and completed family size in Europe. Incipient decline of the two-child family model. In: Demographic Research Special collection 7: Childbearing Trends and Policies in Europe 19,2: 47-72. https://doi.org/10.4054/DemRes.2008.19.4

Frejka, Tomas; Gietel-Basten, Stuart 2016: Fertility and family policies in Central and Eastern Europe after 1990. In: Comparative Population Studies 41,1: 3-56. https://doi.org/10.12765/CPoS-2016-03 
Frejka, Tomas; Zakharov, Sergei 2013: The apparent failure of Russia's pronatalist family policy. In: Population and Development Review 39,4: 635-647.

https://doi.org/10.1111/j.1728-4457.2013.00631.x

Gauthier, Anne Hélène; Hatzius, Jan 1997: Family benefits and fertility: an econometric analysis. In: Population Studies 51,3: 295-306. https://doi.org/10.1080/0032472031000150066

Gauthier, Anne H. 2007: The impact of family policies on fertility in industrialized countries: a review of the literature. In: Population Research and Policy Review 26,3: 323-346. https://doi.org/10.1007/s11113-007-9033-x

Gerber, Theodore P. 2006: Getting paid: wage arrears and stratification in Russia. In: American Journal of Sociology 111,6: 1816-1870. https://doi.org/10.1086/499511

Goldstein, Joshua; Sobotka Tomáš; Jasilioniene Aiva 2009: The end of lowest-low fertility? In: Population and Development Review 35,4: 663-700.

Hoem, Jan M. 1993: Public policy as the fuel of fertility: effects of a policy reform on the pace of childbearing in Sweden in the 1980s. In: Acta-Sociologica 36,1: 19-31. https://doi.org/10.1177/000169939303600102

Hoem, Jan; Prskawetz, Alexia; Neyer, Gerda 2001: Autonomy or conservative adjustment? The effect of public policies and educational attainment on third births in Austria, 1975 96. In: Population Studies 55,3: 249-261. https://doi.org/10.1080/00324720127700

Human Fertility Database: Max Planck Institute for Demographic Research (Germany) and Vienna Institute of Demography (Austria) [www.humanfertility.org, 20.11.2020].

Kohler, Hans-Peter; Billari, Francesco C.; Ortega, José Antonio 2002: The Emergence of Lowest-Low Fertility in Europe during the 1990s. In: Population and Development Review 28,4: 641-680. https://doi.org/10.1111/j.1728-4457.2002.00641.x

Kohler, Hans-Peter; Kohler, Iliana 2002: Fertility decline in Russia in the early and mid1990s: the role of economic uncertainty and labour market crises. In: European Journal of Population 18: 233-262. https://doi.org/10.1023/A:1019701812709

Kohler, Hans-Peter; Ortega, José Antonio 2002: Tempo-adjusted period parity progression measures, fertility postponement, and completed cohort fertility. In: Demographic Research 6,6: 92-144. https://doi.org/10.4054/DemRes.2002.6.6

Kohler, Hans-Peter; Philipov, Dimiter 2001: Variance effects in the Bongaarts-Feeney formula. In: Demography 38,1: 1-16. https://doi.org/10.1353/dem.2001.0004

Kohler, Hans-Peter; Ortega, José Antonio 2004: Old insights and new approaches: Fertility analysis and tempo adjustment in the age-parity model. In: Vienna Yearbook of Population Research 2: 57-89. https://doi.org/10.1553/populationyearbook2004s57

Kreyenfeld, Michaela; Andersson, Gunnar; Pailhe, Ariane 2012: Economic uncertainty and family dynamics in Europe: Introduction. In: Demographic Research 27,28: 835852. https://dx.doi.org/10.4054/DemRes.2012.27.28

Kreyenfeld, Michaela 2004: Fertility Desicions in the FRG and GDR: An Analysis with Data from the German Fertility and Family Survey. In: Demographic Research 3,11: 275-318. https://doi.org/10.4054/demres.2004.s3.11

Lalive, Rafael; Zweimuller, Josef 2009: How does parental leave affect fertility and return to work? Evidence from two natural experiments. In: The Quarterly Journal of Economics 124,3: 1363-1402. https://doi.org/10.1162/qjec.2009.124.3.1363

Lutz, Wolfgang; O'Neill, Brian C.; Scherbov, Sergei 2003: Europe's population at a turning point. In: Science 299,5615: 1991-1992. https://doi.org/10.1126/science.1080316 
Ortega, José Antonio; Kohler Hans-Peter 2002: Measuring low fertility. Rethinking demographic methods. MPIDR Working Paper 2002-001. Rostock: Max Planck Institute for Demographic Research.

Philipov, Dimiter; Kohler, Hans-Peter 2001: Tempo effects in the fertility decline in Eastern Europe: Evidence from Bulgaria, the Czech Republic, Hungary, Poland, and Russia. In: European Journal of Population 17: 37-60. https://doi.org/10.1023/A:1010740213453

Rallu, Jean-Louis; Toulemon, Laurent 1994: Period fertility measures: the construction of different indices and their application to France, 1946-89. In: Population: An English Selection 6: 59-93.

Ranjan, Priya 1999: Fertility behaviour under income uncertainty. In: European Journal of Population 15: 25-43. https://doi.org/10.1023/A:1006106527618

Rosstat 2017: Demographicheskii ezhegodnik 2017 [Demographic Yearbook 2017] Rosstat: tfg.

Sobotka, Tomáš 2003: Tempo-quantum and period-cohort interplay in fertility changes in Europe. Evidence from the Czech Republic, Italy, the Netherland, and Sweden. In: Demographic Research 8,6: 151-214. https://doi.org/10.4054/DemRes.2003.8.6

Sobotka, Tomáš 2004: Is lowest-low fertility in Europe explained by the postponement of childbearing? In: Population and Development Review 30,2: 195-220. https://doi.org/10.1111/j.1728-4457.2004.010_1.x

Sobotka, Tomáš 2011: Fertility in Central and Eastern Europe after 1989: collapse and gradual recovery. In: Historical Social Research / Historische Sozialforschung 36,2: 246-296. https://doi.org/10.12759/hsr.36.2011.2.246-296

Sobotka, Tomáš; Lutz, Wolfgang; Philipov, Dimiter 2005:"Missing births": decomposing the declining number of births in Europe into tempo, quantum and age structure effects. Vienna: Vienna Institute of Demography.

Schultz, T. Paul 1973: A Preliminary Survey of Economic Analyses of Fertility. In: American Economic Review 63,2: 71-78.

Schultz, T. Paul 1981: Economics of Population. Reading (Massachusetts): AddisonWesley Publishing Company.

Schultz, T. Paul 2001: The Fertility Transition: Economic Explanations. Economic Growth Center Discussion Paper No. 833 [https://ssrn.com/abstract=286291, 19.08.2021].

Spéder, Zsolt; Murinkó, Lívia; Oláh, Lívia Sz. 2017: Sailing close to the wind? The effects of third birth policies in post-communist Hungary. In: Working Papers on Population, Family and Welfare 27. https://doi.org/10.21543/WP.2017.27

Van Imhoff, Evert 2001: On the impossibility of inferring cohort fertility measures from period fertility measures. In: Demographic Research 5,2: 23-64. https://doi.org/10.4054/DemRes.2001.5.2

Willis, Robert J. 1973: A new approach to the economic theory of fertility behavior. In: Journal of Political Economy 81,2: 14-64. https://doi.org/10.1086/260152

Zakharov, Sergei 1997: Fertility trends in Russia and the European New Independent States: crisis or turning point? In: Population Bulletin of the United Nations 40/41: 292-317.

Zakharov, Sergei; Ivanova, Elena 1999: Fertility decline and recent changes in Russia: On the threshold of the second demographic transition. In: DaVanzo, Julie; Farnsworth, Gwen (Eds.): Russia's demographic crisis. Santa Monica, CA: RAND: 36-82. 
450 - Asiya Validova

Yi, Zeng; Land, Kenneth C. 2001: A sensitivity analysis of the Bongaarts-Feeney method for adjusting bias in observed period total fertility rates. In: Demography 38,1: 17-28. https://doi.org/10.1353/dem.2001.0010

Asiya Validova ( $\bowtie)$. University of Texas at San Antonio. San Antonio, United States. E-mail: asiya.validova@utsa.edu 


\section{Appendix}

\section{A1 Description of the pronatalist policy measures introduced in Russia in 2007}

1) Increase in pregnancy, birth and child allowance. The law extended monthly child benefits to nonworking women (previously, they were available only to working women on maternity leave). In addition, the birth related allowance included a payment for pregnant women who register during early pregnancy at a local medical practice, and a lump-sum payment at the time of childbirth.

2) Provision of favourable parental leave conditions (in terms of remuneration and leave length). The leave included maternal leave (70 calendar days before and after childbirth with payment of 100 percent of average earnings for 12 months prior to leave, with a set ceiling for all employed women, and also a small payment for unemployed), paid parental leave until the child reaches 18 months ( 40 percent of average earnings with a ceiling and minimum payment), and unpaid leave until the child reaches 36 months.

3) "Maternal (family) capital". The maternal capital is provided to mothers of second and higher order births and is given as a certificate and may not be transformed into cash. At the time of its introduction in 2007 , the sum was 250,000 roubles $(\$ 9,423)$. Until 2015 the payment was annually adjusted for inflation, but in 2016 this adjustment was cancelled. Within the ten-year period from 2007 to 2017 the amount of "maternal capital" grew from 250,000 roubles $(\$ 9,423)$ to 453,000 roubles $(\$ 7,530)$, representing an 81.2 percent increase in national currency. However, it should be noted that the price level increased by 139.6 percent within the period, as the Russian rouble also lost substantially in value throughout the last decade.

"Maternal capital" can be used for several purposes listed in the Federal Law upon a child reaching the age of 3 (except for housing conditions improvements where the baby-bonus can be used immediately); as a result, the first payments were initiated in 2010. More specifically, maternal capital can be used for the following purposes:

- acquisition of housing or improvement of living conditions (buying an apartment, building a house, paying a mortgage, undertaking basic repairs and renovation etc);

- children's education (money can be used to pay for the education of all children in the family in different forms);

- mother's retirement (by investing the maternal capital money in the private pension fund to increase the level of the mother's retirement income).

4) Child-care subsidies and tax benefits. Subsidies for child-care services (for state child-care institutions) were differentiated by birth order: while the federal budget covered 20 percent of the preschool fee for the first child, the subsidy increased 
to 50 percent for the second and 70 percent for the third and subsequent children. Tax deductions (effective from 2012) for parents were insignificant, with the exception of tax credits for parents of children with disabilities.

\section{A2 Gender and Generation Survey 2011 - Graphical Analysis}

A question in the Gender and Generation Survey 2011 was specifically designed to decompose the timing and quantum effects of the family policy of 2007. The exact nature of the policy is not specified in this questionnaire, the question is rather broad and captures the respondents' (both male and female respondents are sampled) perceptions of the effect of the policy on their decision to have children (without specification of a child order). However, the design allows a choice of three possible answers to the question of whether the family policy affected their decision to have another child: 1) positive effect, had a child earlier than planned (timing effect); 2) positive effect, had a child that was not initially planned (quantum effect); 3) no effect, had our children as planned. Across all age groups, the percentage of respondents who stated that they had a child that was not planned prior to the demographic policy was larger than that of women who had their child earlier than planned. Older respondents demonstrated a clearer dominance of the quantum effect over the timing effect, but the overall positive effect of the government's measures was reported by a very low percentage of respondents (Fig. A1).

Fig. A1: Did the introduction of demographic policy in 2007 affect your decision to have additional child?

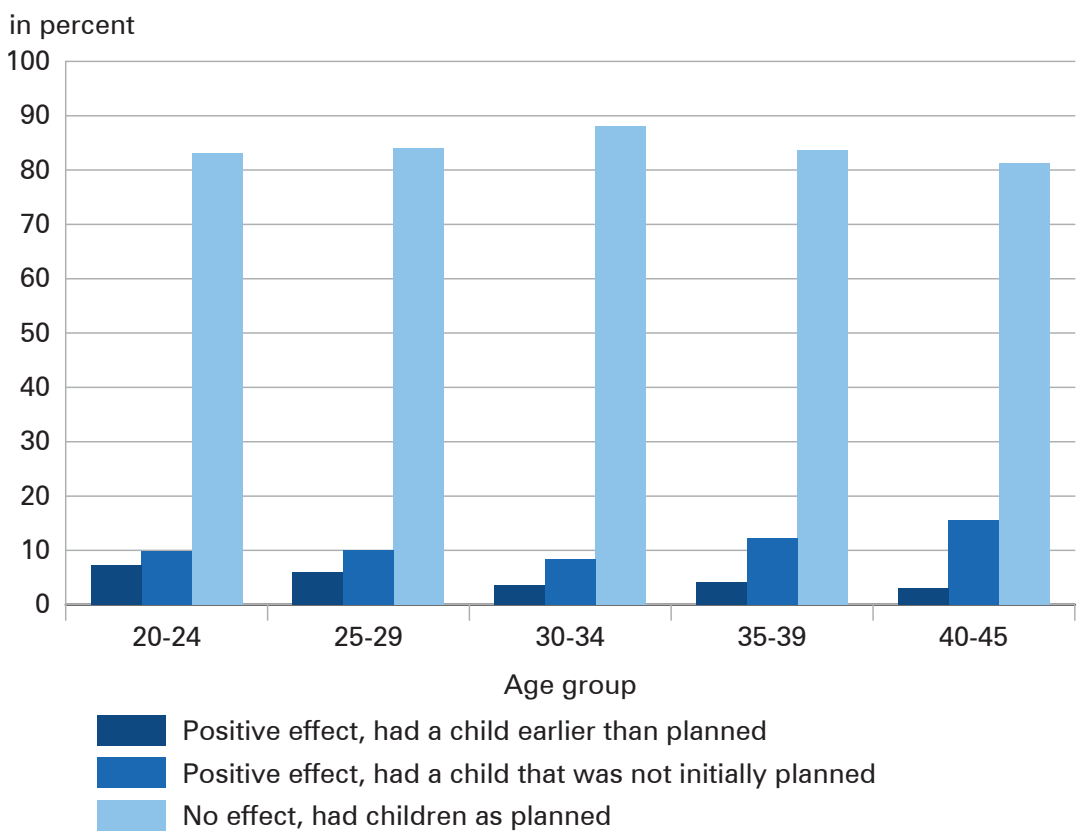

Source: Own calculations from Gender and Generation Survey Russia 2011 


\section{Comparative Population Studies}

WWW.comparativepopulationstudies.de

ISSN: 1869-8980 (Print) - 1869-8999 (Internet)

\section{Published by}

Prof. Dr. Norbert F. Schneider

Federal Institute for Population Research D-65180 Wiesbaden / Germany

\section{(c) BY-SA}

2021

\section{Managing Editor}

Prof. Dr. Johannes Huinink

Dr. Katrin Schiefer

\section{Editorial Assistant}

Beatriz Feiler-Fuchs

Wiebke Hamann

\section{Layout}

Beatriz Feiler-Fuchs

E-mail:cpos@bib.bund.de

\section{Scientific Advisory Board}

Karsten Hank (Cologne)

Michaela Kreyenfeld (Berlin)

Marc Luy (Vienna)

Natalie Nitsche (Rostock)

Zsolt Spéder (Budapest)

Rainer Wehrhahn (Kiel)

\section{Board of Reviewers}

Bruno Arpino (Barcelona)

Kieron Barclay (Rostock)

Laura Bernardi (Lausanne)

Gabriele Doblhammer (Rostock)

Anette Eva Fasang (Berlin)

Michael Feldhaus (Oldenburg)

Tomas Frejka (Sanibel)

Alexia Fürnkranz-Prskawetz (Vienna)

Birgit Glorius (Chemnitz)

Fanny Janssen (Groningen)

Frank Kalter (Mannheim)

Stefanie Kley (Hamburg)

Bernhard Köppen (Koblenz)

Anne-Kristin Kuhnt (Duisburg)

Hill Kulu (St Andrews)

Nadja Milewski (Wiesbaden)

Roland Rau (Rostock)

Thorsten Schneider (Leipzig)

Tomas Sobotka (Vienna)

Jeroen J. A. Spijker (Barcelona)

Heike Trappe (Rostock)

Helga de Valk (The Hague)

Sergi Vidal (Barcelona)

Michael Wagner (Cologne) 